\title{
Evolutionary analysis of five bryophyte families using virtual fossils
}

\author{
by \\ Richard H. Zander \\ Missouri Botanical Garden, P.O. Box 299, St. Louis, MO 63166-0299 U.S.A. richard.zander@mobot.org
}

\begin{abstract}
Zander, R.H. 2009. Evolutionary analysis of five bryophyte families using virtual fossils. Anales Jard. Bot. Madrid 66(2): 263-277.

Traditional taxa paraphyletic or polyphyletic on a molecular phylogenetic tree may be interpreted as populations of surviving ancestors that are evolutionarily static in expressed traits though labile in DNA traits used to track genetic continuity. In those cases in which re-evolution (convergence) of such taxa is deemed improbable, such heterophyly may be used to infer evolutionary series of virtual fossils reflecting macroevolution. Descent with modification of taxa is here demonstrated by reinterpreting published cladograms of molecular studies of Dicranaceae, Pottiaceae, Grimmiaceae, Hypopterygiaceae, and Mniaceae as taxon trees. Given this argument, superimposed inferred ancestors are support for the theory of punctuated equilibrium.
\end{abstract}

Keywords: virtual fossil, heterophyly, punctuated equilibrium, taxon tree, evolution, autophyletic, Grimmiaceae, Hypopterygiaceae, Mniaceae, Pottiaceae.

\section{Introduction}

It has long been recognized that phylogenetic analysis does not model evolution of sequences of named ancestral and descendant taxa, i.e. genealogies, but demonstrates the evolution of characteristics as branching lines of trait changes (e.g., Bowler, 1989: 345-346; Farjon, 2007; Hörandl, 2006, 2007) for exemplars of named terminal taxa. Of three particular taxa, two are more likely to share an ancestor but that ancestor is generally not identified as a taxon different from its descendants; it is simply represented in phylogenetics by an unnamed node, or "common ancestor" of descendant lineages. When fossils are at hand, however, they are potentially more informative of evo-

\section{Resumen}

Zander, R.H. 2009. Análisis evolutivo de cinco familias de briofitas empleando fósiles virtuales. Anales Jard. Bot. Madrid 66(2): 263-277 (en inglés).

Los táxones parafiléticos o polifiléticos tradicionales en un árbol molecular filogenético pueden interpretarse como poblaciones de ancestros supervivientes que están evolutivamente estáticos en los caracteres expresados a través de lábiles en los caracteres ADN que se emplean para seguir la continuidad genética. En esos casos en los cuales la re-evolución (convergencia) de tales táxones se considere improbable, la heterofilia puede usarse para inferir series evolutivas de fósiles virtuales que reflejan la macroevolución. El descenso con modificación de táxones se demuestra con la interpretación publicada de los cladogramas de estudios moleculares de Dicranaceae, Pottiaceae, Grimmiaceae, Hypopterygiaceae y Mniaceae como árboles taxonómicos. En vista de este argumento, resulta que los ancestros inferidos superimpuestos apoyan la teoría del equilibrio puntuado.

Palabras clave: fósil virtual, heterofilia, equilibrio puntuado, árbol taxonómico, evolución, autofilético, Grimmiaceae, Hypopterygiaceae, Mniaceae, Pottiaceae.

lution as descent with modification (Hall, 2003) of taxa because bioroles may be inferred from expressed trait combinations. In phylogenetic analysis, ancestral mapped morphological or molecular traits, though presented as sequential, remain atomized. Attempts to infer soft tissues in geologic fossils also deal with individual traits. For instance, in extant phylogenetic bracketing (Witmer, 1995, 1998), a fossil lineage bracketed by two lineages each sharing one particular trait in their extant taxa would be expected to also have that trait, but features not present in both bracketing lineages would be expected to be absent in the fossil. This method does not rely on and explain, however, para- or polyphyly. 
Of particular importance for the present analysis is the idea that a split in a molecular lineage is not necessarily a speciation event. It could signal any isolation event, sometimes followed by phenotypic stasis of the isolated population, resulting in a surviving ancestor. Identification of a surviving ancestor as a kind of living fossil may be done by (1) identification of a geologic fossil with an extant taxon; (2) biosystematic and cytogenetic studies, particularly in the case of "quantum" or local evolution (Lewis, 1962; Grant, 1971; Levin, 2001), the budding of a descendant species from a peripheral ancestral population, which are identifiable, for instance, as in the event of apparent daughter species being all more similar to an apparent parent than to each other; (3) the recent method of Theriot (1992) inferring a surviving ancestor in a group of diatoms by evaluating a morphologically based cladogram and biogeographical information; (4) the somewhat more simplistic and problematic selection of a surviving ancestor as one lacking autapomorphies on a polytomous morphological clade (Wiley \& Mayden, 2000: 157; discussion by Zander, 1998); or (5) the method of virtual fossils used here.

When exemplars of different taxa are clustered together on a molecular tree, it is impossible to satisfactorily infer the phenotype of the shared ancestor or ancestors. It could be the phenotype of any one of the exemplars or even of a taxon of entirely different phenotype. When exemplars of the same taxon are clustered together on a molecular tree, it is straight-forward to infer that the phenotype of the immediate shared ancestor is that of the exemplars, rather than all exemplars resulting from multiple convergences from an ancestor of a different phenotype. If the exemplars are all one species, the ancestor is that species. If they are of different species of one genus, the ancestor may be inferred to be that genus; or if genera, then their family, and so on. If two such clusters are sister groups, one may infer a particular ancestor for each of both clusters, but the phenotype of the immediate shared ancestor of the two clusters is impossible to infer. It could be one or the other or a different extinct or unstudied taxon of perhaps intermediate phenotype.

A solution may be found if exemplars of the same taxon are separated by a lineage of a different phenotaxon. And in spite of such separation (phylogenetic disjunction) on a cladogram the exemplars of the former paraphyletic taxon, when examined for possible mistaken taxonomy, remain assuredly that taxon. Given that the circumscription of traditional phenotaxa, at least those of modern studies, commonly involve conservative, gapped phenotypic traits, and that total convergence or crypsis is improbable or less probable (Jardine \& Sibson, 1971: 144) than other explanations, simply enforcing monophyly by taxonomically recognizing cryptic species, genera or families may be less productive scientifically than examining other explanations. The point of traditional taxonomy is to make complete evolutionary convergence improbable, and this applies at any taxonomic level. Classification is here presented as a major source of information about evolution needing only reliable information on genetic continuity to reveal taxic steps. Even morphological phenocopy involving two or more taxa that lose traits when highly reduced (e.g. in high elevation habitats) commonly allows retention of one or more conservative traits that allow accurate identification (Zander, 1977: 261), or when unidentifiable, it is because the reduced plants are intermediate or generalist in form. Thus, Dollo's Rule (Hall, 2003) is at least methodologically applicable at the organismal level of a unified combination of traits, while many individual morphological characters may be quite homoplastic (Endress, 1996: 313).

The null hypothesis is a fully nested set of phenotaxa, without indication of descent with modification of such taxa (Fig. 1). The null hypothesis for the evolution of expressed traits in a genus is that any phenospecies may be derived from any other in spite of any inferred phylogenetic trees, which give no definite information on the phenotype of any ancestor. Falsification of that null is demonstration of one or more phenoancestors diagramed (e.g., Fig. 5) by moving these (along with all descendants) out of the group as a linked sequence, and leaving a "residuum" of unordered taxa. By extension, with less resolution, one phenogenus of a family may be derived from any other, unless an ancestor is demonstrable.

When exemplars of the same taxon (particularly of the same species) are distant from each other on a molecular tree, being separated by other taxa at least as sister lineages, the homoplasy is commonly either explained as (1) evidence of that taxon or something quite like it being basal or ancestral to a portion of the cladogram, or (2) cryptic or sibling taxa that need different taxonomic names. Textbook examples of the former are given by Futuyma (1998: 456, 470), citing Moritz \& al. (1992) where coastal and Sierran Californian subspecies of the salmander Ensatina eschscholtzii "appear to have been derived from" subsp. oregonensis, and citing Hey \& Kliman (1993) and Kliman and Hey (1993) for the Drosophila melanogaster species group where the paraphyletic $D$. simulans "gene copies are traced back to a 'deeper' common 
ancestor than in any other species." Rieseberg and Brouillet (1994) discuss mechanisms for evolution of monophyletic daughter taxa from paraphyletic parental taxa through geographically local models of speciation. All this assumes that the molecular analysis has accounted for any homoplasy introduced into the analysis by inappropriate technique, e.g. wrong model (Alfaro \& Huelsenbeck, 2006) or inappropriate data, e.g., incomplete concerted evolution (Doyle, 1996).

Nelson \& al. (2003) refuted Brummitt's (2002) assertion that paraphyly implies an ancestor. They asseverate that "In practice, extinct ancestral taxa are seldom of concern, because organisms credibly representing them are seldom if ever in hand." Here I strongly suggest that exemplars of the same taxon that are distant on a molecular phylogenetic tree are credible representatives of ancestors of themselves and all lineages intermediate on the cladogram. An extensive discussion of paraphyly and the possible inference of ancestry is given by Wiley \& Mayden (2000), who wrote: "Only the paraphyletic taxa of evolutionary taxonomy can be ancestors". It is clear, however, that if evolution is descent with modification, particularly of taxa rather than traits, then sister-group analysis (cladistics) is only an indirect guide to evolution, while ancestor-descendant relationships are direct inferences of evolution.

Although imputing an ancestral status to paraphyletic taxa is not particularly new, a formal method for using heterophyly (i.e., either paraphyly or polyphyly) as it implies an ancestor surviving in two or more isolated populations that may be used as a virtual fossil embedded in a molecular phylogenetic tree, ancestral to all dependent (more terminal on the tree) lineages on the cladogram, to create evolutionary or taxon trees. The alternative hypothesis is illustrated

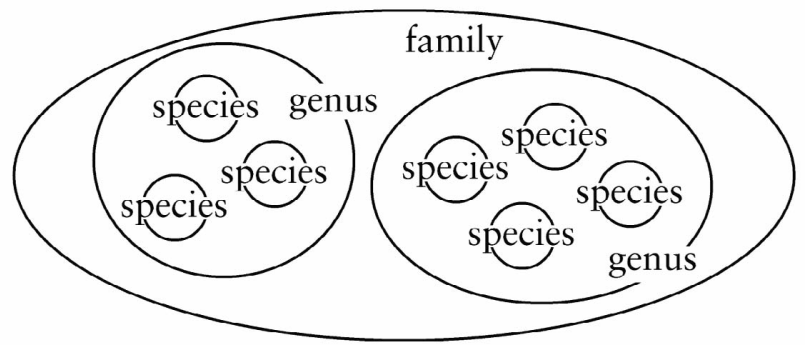

Fig. 1. A diagram of the null hypothesis of all taxa nested because no evolutionary ordering of phenoancestors is inferable. Molecular lineages can provide continuity between ancestors but the phenotype (resolvable at some taxonomic level) of ancestors is unknown beyond the general feeling that ancestors should be somewhat similar to nearby exemplars. by Fig. 2; for traditional taxa $A$ and $X$, phenotaxon $A$ * is ancestor of exemplars $A_{1}, X$, and $A_{2}$. Exemplar $X$ is inserted to indicate that heterophyly is methodologically allowable though $\mathrm{X}$ is not strictly necessary for inference of the virtual fossil $A *$, but heterophyly demonstrates any descendents of the virtual fossil beyond the exemplars of the same taxon. The same kind of inference may be made for phenotaxon $\mathrm{B}$, and then ancestors $A *$ and $B *$ are sequentially ordered on a molecular cladogram as diagramed in Fig. 2 to infer macroevolution on the molecular tree. Convergence or parallelism occurring to develop what is essentially the same taxon two or more times from a different taxon or taxa, short of orthogenesis (an internal evolutionary goal), is here taken to have a much lower probability than existence of populations of surviving ancestors. Although evolution of trait combinations is doubtless ergodic (all possible combinations explored, including duplication), evolutionary stasis of each of two isolated populations I believe is more acceptable an explanation of heterophyly given that many traits, particularly those at higher taxonomic levels are chosen as important in taxonomy for their conservative nature, perhaps because their DNA is more vigorously repaired than that of other traits. Trait combinations, judging from evaluations of fossil groups over time in the literature, apparently diverge from a "root" combination in a kind of drunkard's

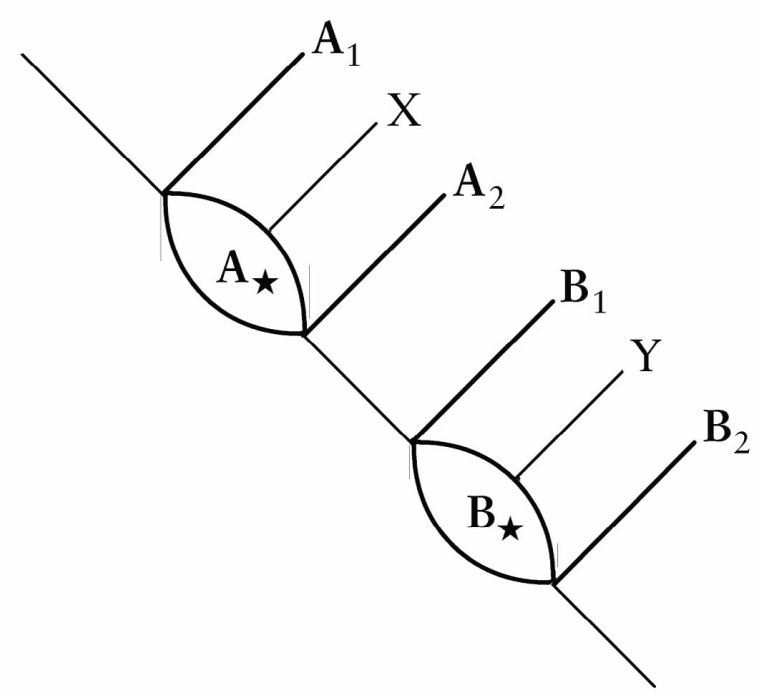

Fıg. 2. Demonstratıon cladogram ot sequentıal evolutıon of taxa as inferred from heterophyly on a molecular cladogram. Exemplars $A_{1}$ and $A_{2}$, and $B_{1}$ and $B_{2}$ allow inferences of virtual fossils $A^{*}$ and $B^{*}$, exhibiting sequential evolution of taxa $A *$ from $B *$ (when cladogram is rooted below $B^{\star}$ ). Exemplars $X$ and $Y$ are interspersed to signal heterophyly in this contrived example. Alternatively, again as a demonstration, $A^{*}$ and appended lineages could replace $Y$, as a different but expected form of evolutionary nesting, with the molecular cladogram indicating the correct sequence. 
walk (divergence distance a function of the square root of elapsed time), restricted only by phylogenetic constraint (limitation on evolution of one complex organism into another of much different complexity) and selection on some of the traits or their combinations. Conservative traits, phylogenetic constraint, and a general slow divergence of trait combinations (except for static populations) act against fully cryptic convergence in spite of clear convergence of some traits in response to adaptation to similar environments.

The idea that sister lineages must have different taxonomic names if there is a split in a molecular tree is purely definitional, because isolation does not ensure speciation unless speciation is simply defined as isolation, and anagenesis is conceived in molecular phylogenetics as any changes in DNA, including noncoding. In the present paper a molecular tree demonstrates genetic continuity of lineages (to the extent it is reliable), but not necessarily series of speciation events. Macroevolution is best described by descent with modification of taxa, not morphological traits atomized on molecular tree.

An example of heterophyletic information on evolution is the increasingly common discovery of what are generally viewed as phylogenetically isolated cryptic species, e.g. the 14 cryptic or nearly cryptic species of bryophytes recently found in mosses by Shaw (2001), also the cryptic species of Hedenäs (2008) and

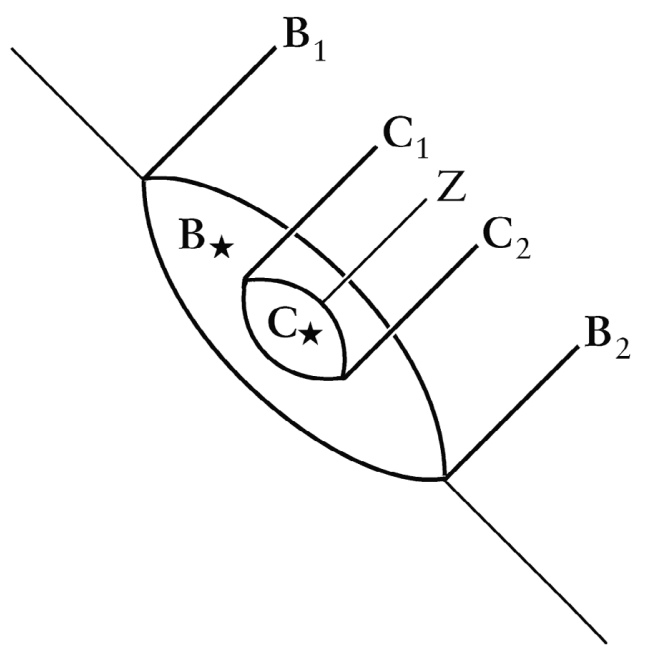

Fig. 3. Demonstration cladogram of a "double ancestor" or overlapping virtual fossils that may be explained by, in this instance, a very short and unresolved branch connecting $B^{*}$ and $C *$ due perhaps to punctuated equilibrium rather than double convergence. Exemplars $C_{1}$ and $C_{2}$, which are paraphyletic because of autophyletic exemplar $Z$, which is sister to $C_{1}$, infer ancestor $C^{*}$, which itself is embedded in or overlapping of ancestor $B^{*}$, inferred from phylogenetically disjunct exemplars $B_{1}$ and $B_{2}$.
Hedenäs and Eldenäs (2007), but which are more probably surviving phylogenetically and geographically disjunctive populations of shared ancestors. The isolated populations accumulate different DNA mutations over time but may be morphologically static through time through some process like stabilizing evolution (Foote \& Miller, 2006). Persistence of some or even a great proportion of evolutionarily static populations or species (Guillaumet \& al., 2008; Leschen \& al., 2008; Shen \& al., 2008) is implied by the increasingly supported punctuated equilibrium theory of Eldredge and Gould (1972), Gould \& Lewontin (1979), and Gould \& Eldredge (1977, 1993), which may be valid for many or most taxa, though gradual (Futuyma, 1998: 114) or stepwise transitions have been demonstrated (e.g., Deméré \& al., 2008; Benton \& Pearson, 2001).

The present paper emphasizes virtual fossils at the genus level and above. Do supraspecific taxa evolve? Discussions of selection at the genus level and above are given by Rensch (1960) and Stebbins (1974), while Stanley (1975) has promoted the idea of species selection, with differential speciation rates for different species favoring those with high speciation rates, a kind of natural selection operating on species in supraspecific taxa rather than individuals in a population. In the present paper, readers may view virtual fossils as either simply representing populations or species evolving in the past, or as higher taxa evolving by selective extinction of species, with results similar to balancing, directional and disruptive selection.

An autophyletic taxon is one that causes another taxon to be paraphyletic because of its recognition at a particular rank, a taxonomic level that indicates evolutionary importance due to particular unique autapomorphic traits. In a new classification of mosses by Goffinet \& al. (2008), although the family name Ephemeraceae is used in their introduction in discussion of the evolutionary importance of its autapomorphies, that name is entirely suppressed in the actual classification apparently because those autapomorphies are of no value in determining sister-group relationships (i.e., are not phylogenetically informative). Two other families, Cinclidotaceae and Splachnobryaceae are entirely absent (the classification lacks synonymy) apparently because their exemplars are imbedded in the Pottiaceae in other studies, thus making them autophyletic and the Pottiaceae paraphyletic. The loss of evolutionary information on ancestor-descendant relationships (Dayrat, 2005) flagged by these names apparently solely due to enforcement of strict monophyly is particularly trou- 
bling as taxonomic classifications inform other fields, such as biodiversity studies, evolution, biogeography, and ecology.

\section{Methods}

The present method uses heterophyly of phenotaxa to infer a surviving ancestor (Zander, 2008b) with inbetween (bracketed) lineages seen as descendants. Essentially, if one can map morphological traits probabilistically on a molecular tree, then mapping natural taxa on a molecular tree as composites of many expressed traits is only prevented by intransigent insistence on phylogenetic monophyly, an artificial classification system. Thus, two exemplars of one species that are separated on a molecular tree by an exemplar of a different phenospecies imply a shared ancestor of all three that is identical or nearly identical to the two isophenes. A surviving ancestor at the genus level is implied by two phylogenetically disjunctive (distant on a cladogram, heterophyletic) species of the same genus. Minimally, a phylogenetic disjunction involves
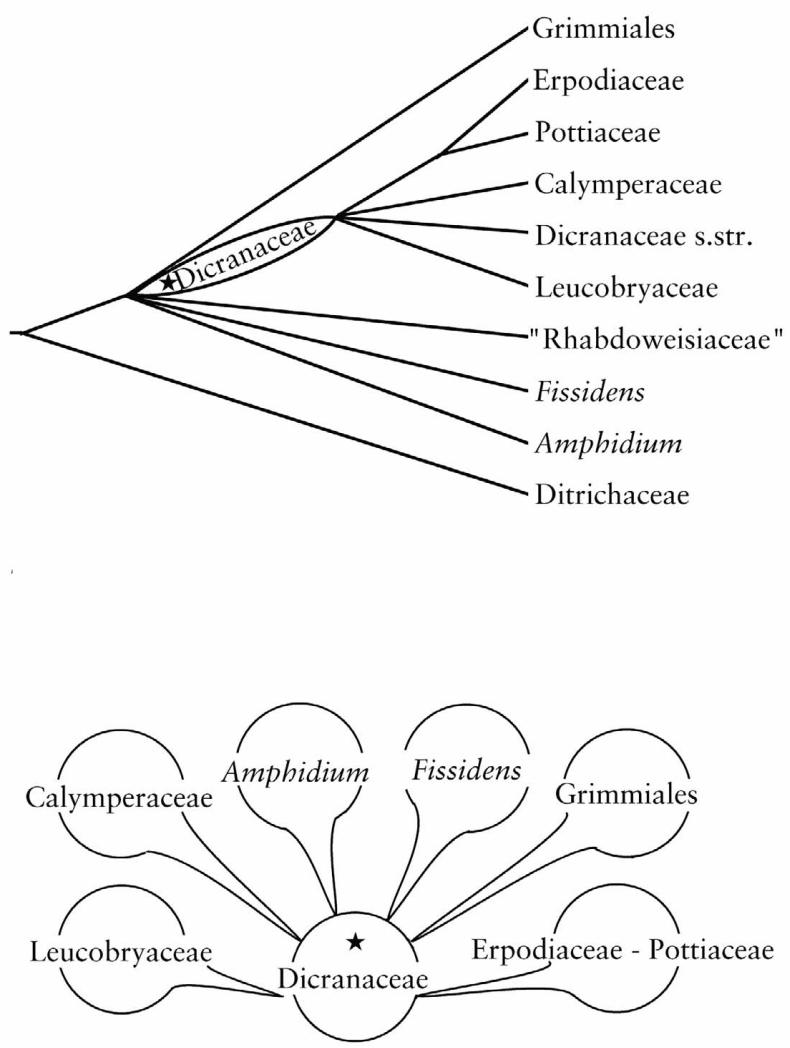

Fig. 4. Cladogram showing position of Dicranaceae virtual fossil (starred), and best resolvable taxon tree for Dicranaceae and descendant moss families. See text for details of trait changes involved in macroevolution of these taxa. two exemplars of one taxon with an exemplar of a different taxon as sister group to one of them. The null hypothesis (or state of nature) is that there is no phenotypic descent with modification inferable, and all phenotaxa are completely nested (Fig. 1). This is falsified by demonstration that one of the extant phenospecies represented by a pair of surviving ancestors distant on a molecular tree, implying a virtual fossil is "buried" in the cladogram, and any other taxa between the two exemplars on the molecular tree are descendants. Molecular phylogenies provide the continuity that allows creation of a taxon tree, which is a sequentially organized, sometimes branching, ancestordescendant diagram of named, diagnosable taxa. It is a phylogeny but not a cladogram in the sense that evolutionary relationships of taxa represented by exemplars are sequential, not based on relative distance from shared unnamed ancestors.

Given the assumption that surviving taxa are more probable than convergence of taxa, rejection of the virtual fossil requires demonstration that the phylogenetically disjunctive isophenotype exemplars are dif-

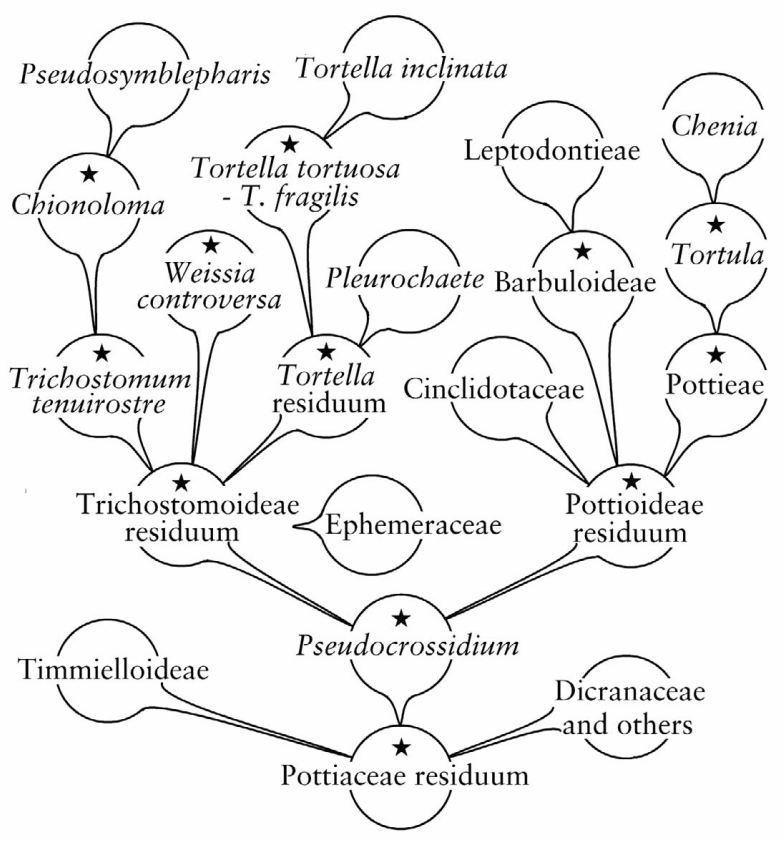

Fig. 5. A taxon tree (stylized Besseyan cactus) of the Pottiaceae, showing heterophyletic ancestral taxa (starred) some of which are ancestral consensus taxa ("residua") of assorted species (and sometimes genera) that cannot be further internally evolutionarily ordered from available data. Many exemplar species (not shown) are also attached variously about the taxon tree, and may be inferred from the cladogram of Zander (2007a) or Werner \& al. (2005). 
ferent at the species level (minimally following a different evolutionary track involving the phenotype, or some other species definition that is not merely defined by a split in a morphological or molecular tree), or come from different ancestors. Sometimes disjunction of exemplars of what are only apparently the same taxa (species, genera, etc.) on a cladogram may represent taxa that should, after judicious consideration, be taxonomically separated into two. One must be aware, however, that any small number of, for instance, species might be split randomly into two groups and "generic descriptions" written that ostensibly describe such groups (in the main, and with some contrary traits explained as "reversals"), but such morphology may not comprise a robust phenotypic genus with conservative characteristic traits more or less well gapped from related genera, commonly with a distinct evolutionary biorole. Although the importance of gaps between taxa in taxonomy is sometimes deprecated as simply relying on ignorance, particularly when geologic fossils are part of an evolutionary analysis (Gauthier, 2001:33), an evolutionary based taxonomy should reflect the present day results of selection, not simply inferred genetic continuity. Extinct taxa based on geologic fossils, though perhaps well gapped from similar taxa in their day, have trait combinations that reflect evolutionary advantages of past bioroles in long gone habitats and competitive situations, and need to be fit as best possible into present classifications as somewhat evolutionarily incongruent. An evolutionary taxonomy should be expected to change with geologic time.

Apparent homoplasy of traditional groups, sometimes ingenuously characterized as "massive," in any molecular cladogram signals a possible surviving species, genus, family or other taxon (Zander 2007 b,

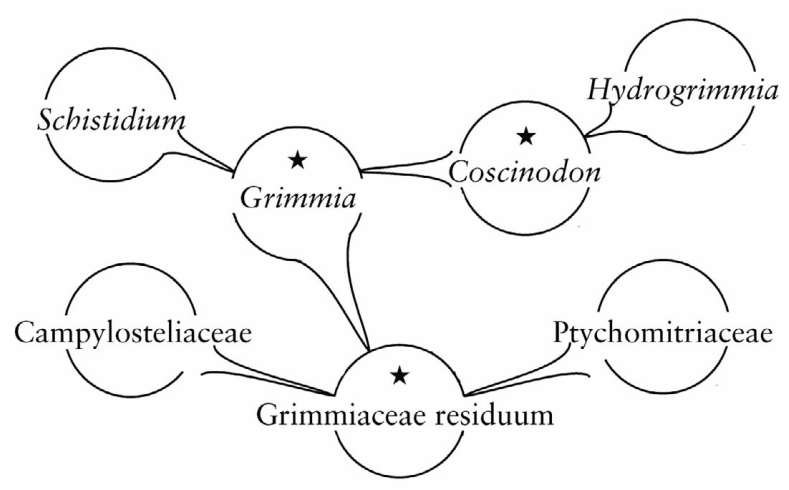

Fig. 6. Grimmiaceae taxon tree based on Hernández-Maqueda \& al. (2008). Heterophyletic inferred ancestors are starred. c). Inferential demonstration of two ancestral phenospecies is made by the presence on a molecular tree of two pairs of such individually phylogenetically isolated isophenes, implying two different ancestors, these, ideally, ordered to show sequential evolution of one from the other. With enough data, this can be extended to identification of many ancestral species in the genus. Such ancestral phenotypes lead to a tree of virtual fossils, or a taxon tree, for instance exemplified as a "Besseyan cactus" (Bessey, 1915; Zander, 2008b), perhaps, with enough data, along the lines of the impressive geologic fossil-based horse genealogy presented by Futuyma (1998: 141) based on McFadden (1992). The analysis may be extended to higher taxonomic categories demonstrating multiple ancestors resolvable only at the phenotypes of the higher taxonomic categories, where the virtual fossil is identifiable only to genus or higher. Clearly, to use the method, one must view heterophyly and homoplasy involving isolated populations leading to apparent molecular parallelism or convergence as a common and expected result of evolution (or sometimes non-evolution) of taxa. With study of increasing numbers of exemplars of particular taxa in any one molecular analysis, particularly of geographically isolated populations or morphologically distant species, a complex tree of sequential evolution of taxa may be demonstrated.

Two kinds of ancestral taxa can be inferred for the taxon tree. (1) A poorly resolved consensus taxon, which is basically the diagnosis of the next higher taxonomic category of a mixed group of phenotaxa for which the evolutionary sequence is unknown. A consensus ancestral taxon is simply the null hypothesis of no evolutionary order based on expressed traits, a nesting of all taxa, as in Fig. 1 and identified as a "residuum" in other figures given here. (2) Surviving ancestors from which may be inferred an identical or nearly identical paraphyletic or even phylogenetically polyphyletic ancestor of the same rank. This would be, for example, one or more ancestral species in a genus, or ancestral genera in a subfamily or family. All such phenotype ancestors may be arranged in progressive evolutionary diagrams with the help of reliable molecular trees (Zander, 2007a). Cronquist (1975) contended that parallelism among closely related taxa is of no import or consequence in taxonomy, and can be ignored. This agrees with the present paper in that parallelism implies no important expressed evolutionary feature that must be reflected in taxonomy. Cronquist (1987) also supported recognition of paraphyletic groups. A critique of his paper by Dongoghue and Cantino (1988) asserted among other things that paraphyletic groups "do not serve as an- 
cestors, and are unacceptable in the phylogenetic system." The present paper rejects the former with a clear alternative, and suggests that the phylogenetic system cannot adequately portray evolution. When morphological and molecular data agree, they may simply be subject to the same bias (neutral evolution, adaptive selection, and even convergence), but when they disagree (and are not simply due to error) then new information may sometimes be deduced.

Molecularly heterophyletic taxa can provide evolutionary data just as parsimoniously informative traits provide phylogenetic data. Phylogenetically polyphyletic taxa are not of necessity evolutionarily polyphyletic - if the phylogenetically disjunct exemplars are determined to be surely the same taxon in phenotype, then the inferred phenotypically identical ancestor of these surviving populations completes the lineage as evolutionarily monophyletic in the sense of being coherently ordered. When one or two lineages of a phylogenetically split taxon are renamed to enforce monophyly, however, as is now common practice, evolutionary data is unfortunately hidden. There is no empiric evidence supporting phylogenetic monophyly as a thing in nature. On the other hand, reinterpreting cladograms with somewhat older nomenclature that reflects morphology (or phenology, to include biorole) alone will best preserve evidence of heterophyly and its evolutionary information.

The reliability of any pair of heterophyletic lineages (or exemplars) implying a surviving ancestor depends on the joint probability of the two lineages being indeed phylogenetically monophyletic and disjunct from each other by at least one internode (which supports a different taxon as a descendant). For example, in the cladogram $\left(\left(A_{1}, B\right) A_{2}\right) C$, for two exemplars of species $A$, namely $A_{1}$ and $A_{2}$, to be patristically distant by one internode such that they imply a shared ancestor $A$ with $B$, depends on the probability of $A 1$ and $B$ being sister groups on a molecular tree, while $A_{1}$ and A 2 must also be involved in calculation of joint probability if these are lineages of multiple species and there is uncertainty that these are not phylogenetically monophyletic. In the preliminary survey here, reliability is commonly quite good for most virtual fossil inferences but, because the method is new, statistical power in distinguishing possible evolutionary features is emphasized over reliability of the taxon tree (see discussion of statistical power by Zander, 2007a).

For this study, several published cladograms were examined to search for inferable sequential evolutionary relationships from evidence of surviving ancestors.

\section{Results}

The evolutionary diagrams or taxon trees (Figs. 4-6) combine consensus ancestral taxa (labeled as "residua") with those inferred from heterophyly, which differ in being evolutionarily resolved through inference of descent with modification of taxa. The ancestral taxa are linked using the genetic continuity provided by phylogenetic information from molecular analyses. Examination of published molecular trees and exemplars named as traditional taxa commonly demonstrates cladistic splitting of what are probably ancestral taxa at various ranks surviving to the present. With increasing numbers of exemplars of particular taxa in recent molecular analyses, this should become more evident. In the figures given here, all linkages are well-supported in the molecular analyses of the literature on which they are based, and the here-inferred virtual fossils are denoted with a star.

Zander (2008a) found that the Dicranaceae was the paraphyletic ancestor of two phylogenetically disjunctive and well-supported reciprocally monophyletic clades, the Dicranaceae s.str. and a lineage of generally small-sized taxa commonly referred to in phylogenetic literature as the "Rhabdoweisiaceae" but with no agreed upon morphological diagnosis to distinguish it from the Dicranaceae. Dicranaceae is here described as a virtual fossil (conceivable as one or more populations resolved only with the morphology of this family), and ancestor of the genera Amphidium and Fissidens, and the families Calymperaceae, Grimmiaceae (as Grimmiales), Leucobryaceae, and the Erpodiaceae and Pottiaceae together sharing a lineage (Fig. 4). Of course, the few exemplars provide poor sampling of the whole family, but may be considered sufficient statistics for the phenotypic center of the family. Thus, the more advanced members of the Dicranaceae, characterized by a morphological main line of evolution (Crum \& Anderson 1980) of narrow, tapered leaves with a strong, single costa and often inflated alar cells, and flat, forking peristome teeth that are vertically pitted-striolate, gave rise to the (1) Leucobryaceae, with glaucous leaves, leaf hydroid strand absent, costa very broad, laminal cells strongly differentiated into chlorophyllose and hyaline cells; and (2) Calymperaceae, with stem central strand absent, laminal cells sometimes papillose, hyaline cancellinae juxtacostally, peristome of 16 segments that are variously ornamented; and (3) Erpodiaceae, being cladocarpic, lacking a costa, laminal cells commonly papillose; and (4) Pottiaceae, with twisted peristome, and leaves with enlarged basal cells and papillose distal cells. The less advanced members of the Dicranaceae that gave 
rise to Amphidium, Fissidens, and Grimmiaceae are presently much reduced in morphology and it may be presumptuous to detail trait changes. A main evolutionary theme, therefore, among families evolving from Dicranaceae involves differentiation and elaboration of laminal cells (and often the costa) by inflation or ornamentation.

Phylogenetically disjunct taxa in molecular studies of Werner \& al. (2004) and Werner \& al. (2005) of the Pottiaceae were translated into virtual fossils and these figured as a "Besseyan cactus" by Zander (2008b) but here presented more simply (Fig. 5). The basal "Pottiaceae residuum" is an unordered group out of which many Pottiaceae taxa have been isolated as virtual fossils (starred). It is established by the strong disjunction on the phylogenetic tree of Timmielloideae and the remainder of the Pottiaceae (Zander, 2007a). The Timmielloideae are derived from the most basal elements of Pottiaceae through elaboration of the laminal cells and reversal of peristome twist; together with the at least tentative identification of Pseudocrossidium as having the apparently primitive traits of broad leaves, commonly ovate to elliptic leaves, rather small distal laminal cells, small size or absence of the adaxial costal stereid band, crescent shape of the abaxial stereid band, and lamina yellow or orange (with occasional red spots) in $\mathrm{KOH}$; and directly giving rise to Trichostomoideae (narrow, plane or marginally incurved leaves with two stereid bands), Pottioideae (broad leaves with recurved margins). The Ephemeraceae (highly reduced morphologically and adapted to evanescent moist habitats) is derived from elements of the Trichostomoideae.

Three species of Barbula are heterophyletic in the same manner as Pseudocrossidium species, with B. bolleana (Müll. Hal.) Broth. (B. sect. Hydrogonium) and B. indica (Hook.) Spreng. (B. sect. Convolutae) placed with the Trichostomoideae, and B. unguiculata Hedw. (B. sect. Barbula) with the Pottioideae. The heterophyly plus the fact that the laminal margins are flat in sections Hydrogonium and Convolutae like those of Trichostomoideae, but recurved in sect. Barbula as per Pottioideae, indicated that the two sections of Barbula may represent to different genera. A study, however, rejects this in that all species are correctly placed in Barbula, or at least the Pottioideae, by the stem section with strong sclerodermis, large cells of outer central cylinder grading into smaller cells within and a strong central strand, leaves deeply grooved along the adaxial surface of the costa, differentiated basal laminal cells extending farthest distally midway between costa and leaf margin, and hydroids evident in the costal section. This is opposed to the Trichosto- moideae's stem section showing poor sclerodermis development, nearly homogeneous central cylinder cells and a small or absent central strand, leaves shallowly channeled adaxially, differentiated basal laminal cells commonly extending to a greater or lesser extent up the margins, and hydroids usually lacking in the costa. Thus, both Barbula and Pseudocrossidium represent deeply buried ancestral taxa, resolvable only as Barbuleae, which would then be the ancestral group of the remainder of the tree (an unordered group distinguishable only as Pottioideae but with Pottieae apparently derived from Barbuleae), including the Cinclidotaceae.

In the Trichostomoideae, Pseudosymblepharis is derived from Trichostomum tenuirostre through Chionoloma by narrowing of the leaves (narrowest in Pseudosymblepharis), thickening of the cells of the stem central cylinder, thickening of the ventral costal stereid band, elaboration of basal laminal cells, and apparently convergent (with Tortella) elaboration of the marginal band of hyaline cells. Arising from the Trichostomoideae residuum by monoicy, sharply incurved distal laminal margins, and adaxially bulging laminal cells, Weissia controversa Hedw. is apparently the ancestor of a number of species of Weissia (not shown). From the Tortella residuum, T. tortuosa (Hedw.) Limpr. and T. fragilis (Drumm.) Limpr. jointly (as a poorly resolved ancestor) give rise to T. inclinata; note that $T$. fragilis may be easily mistaken for $T$. tortuosa when young (Eckel, 1998) and thus the poor resolution here may be in identification of the exemplars. Pleurochaete is clearly derived from Tortella, though not directly from T. tortuosa, through pleurocarpy and elaboration of the hyaline band of marginal laminal cells that does not meld with the basal cells.

Descendents of the Pottioideae include: (1) the family Cinclidotaceae, adapted to aquatic or otherwise hygric habitats; (2) the Barbuleae, with narrow, marginally recurved leaves having two stereid bands leading to Leptodontieae, which have squarrose leaves, commonly lack a stem central strand and ventral costal epidermis, and have reduced peristomes; and (3) the Pottieae, with broad leaves and one costal stereid band, from which are derived Tortula, with stem sclerodermis and hyalodermis both absent, costa transverse section and dorsal stereid band both rounded, hydroid strand usually present, distal portion of leaves $\mathrm{KOH}$ yellow, peristome and capsule in a reduction series, which is itself the ancestor of Chenia, characterized by leaves with sharply pointed marginal teeth ending in a papilla but laminal cells mostly smooth, leaf ending in a more or less distinct spinose cell with thickened walls, upper portion of leaf $\mathrm{KOH}$ 
red. The overall taxon tree seems to fit in broad outlines the morphological cladogram of the family by Zander (1993), but of course the latter does not identify ancestors.

Certain families in Fig. 5 (as "Dicranaceae and others") appear to arise from the Pottiaceae residuum, including the Dicranaceae, Fissidentaceae, Grimmiaceae, Ptychomitriaceae, Seligeriaceae, and Wardiaceae. These apparently contradict Fig. 4, which derives Pottiaceae from the Dicranaceae. This is because the Timmielloideae are more basal than these families by one reliable internode in the analysis of published molecular cladograms by Zander (2007a), on which Fig. 5 is based, while Fig. 4 does not include the strongly basal Timmielloideae in its molecular data set. If Timmielloideae were included in Fig. 4, it would doubtless be basal to the Dicranaceae, possibly resulting in a "double ancestor" (diagramed in Fig. 3 and see discussion) of internodes of Dicranaceae morphology inserted as a unit within the lineage of Pottiaceae morphology. Such double or superimposed ancestors may be best explained by rapid bursts of evolution and associated unresolved short branches coupled with long stasis of isolated populations, confused in analysis by long-branch attraction. In fact, such fully collapsed nested ancestry would be an expected outcome of punctuated equilibrium combined with multiple isolated static populations, and may be taken as additional evidence in support of that theory. Much nesting due to collapse because of many short branches may be a measure of the relative amount of punctuated equilibrium versus gradual change. Additional explanations that might be explored are ancestral balancing selection, long-term or latter-day low levels of hybridization between isolated populations, or a problem with analysis of genetic continuity such as lack of data resulting in an unresolved phylogenetic branch connecting the Pottiaceae and Dicranaceae virtual fossils, or data-destroying extinctions, or by more exotic possibilities such as lateral gene transfer, or epigenetic reversion by reactivation of silenced genes (Caporale, 1993, 2003; Zander, 2007d). The possibility of explanations alternative to convergence, or in this case double convergence, must be countenanced, even though convergence as parallelism from a shared ancestor (B* or C*in Fig. 3) is quite possible through two or more identical events of allopolyploidy over time, or when the same niche is twice involved in speciation from the same ancestor. Certainly additional data should be pursued to help resolve this problem. The particular scientific interest in this discrepancy lies in examination of various mechanisms that explain such contradiction. The use of het- erophyletic exemplars as evolutionary information is still in early days.

Examination of a study (Hernández-Maqueda \& al., 2008) of genera of the moss family Grimmiaceae and related families allowed inference of a rather unambiguous or well-nested evolutionary taxon tree (Fig. 6) of heterophyletic taxa. The Grimmiaceae residuum brackets on the molecular tree and is the ancestor of (i.e., is heterophyletic and includes as descendant lineages), Campylosteliaceae and Ptychomitriaceae (bracketed by Jaffueliobryum and Indusiella) while Grimmia brackets Schistidium and Coscinodon. The latter brackets Hydrogrimmia.

In a study of the moss family Hypopterygiaceae, Shaw \& al. (2008) analyzed six nuclear, plastid and mitochondrial nucleotide sequences of 32 exemplars and found that of four species of Cyathophorum, two were paired near the base of the strongly supported cladogram and two were buried deeply among 10 exemplars of the genus Hypopterygium. Although Shaw $\&$ al. chose to simply transfer the two species bracketed in Hypopterigium to that genus to preserve monophyly, it is clear that the cladogram is also evidence of Cyathophorum being a heterophyletic genus ancestral to several genera bracketed by it in the cladogram ( $A r$ busculohypopterygium, Canalobypopterygium, Catharomnion, Dendrobypotperygium, Hypopterygium, Lopidium) while itself has one of these (Hypopterygium) as ancestor of two of its species. This scenario may be described as another "double ancestor" (see Fig. 3) similar to that discussed above with Dicranaceae and Pottiaceae. In any case, there are two reasons not to accept the transfer of the two species of Cyathophorum to Hypopterygium: (1) preserving phylogenetic monophyly is insufficient reason not to recognize differences at the genus level (particularly when the same level of difference is recognized elsewhere in the cladogram), and (2) inference of a shared isophenotypic ancestor is an explanation far more plausible than total re-evolution of a combination of several major morphological traits (including anisophylly and differentiated laminal border) to converge at the genus level, when such a combination of traits is known to be so conservative as to be valuable taxonomically. Although a two or three unique traits may be assigned to the two autapomorphic Cyathophorum species, the possibility that these are simply randomly selected from among all species of the genus as a multiple tests problem in statistics (Zander, 2007a) has never been evaluated. Because the two species of Cyathophorum are embedded deeply in $\mathrm{Hy}$ popterygium, abrupt re-evolution through reactivation of an evolutionarily advantageous suppressed 
trait complex (Zander, 2007d). Although this appears to be true evolutionary polyphyly, it may also be a case of true saltative evolution (Zander, in prep.). See Vrba (1984) for discussion of linked suites of characters with heterochronic variation.

A molecular evaluation (Harris, 2008) of the moss family Mniaceae demonstrated that Plagiomnium maximoviczii is paraphyletic. If the phylogenetically disjunct exemplars are interpreted as surviving populations of the same ancestor, then $P$. maximoviczii (Lindb.) T.J. Kop. has given rise to several species including P. cordatum T.J. Kop. \& D.H. Norris, P. integrum (Bosch \& Sande Lac.) T.J. Kop., P. novae-zealandiae (Colenso) T.J. Kop., P. rbynchophorum (Harv.) T.J. Kop., P. rostratum (Schrad.) T.J. Kop., and P. vesicatum (Besch.) T.J. Kop. Plagiomnium integrum, however, also survives in two ancestral populations phylogenetically distant on the cladogram, which imply a virtual fossil overlapping that of $P$. maximoviczii. Again, there is apparent double convergence (between three lineages with the morphology of $P$. maximoviczii and two with the morphology of $P$. integrum, which is almost certainly less probable an explanation than, for instance, punctuated equilibrium among multiple surviving ancestors, ancestral balancing selection or hybridization, or the polyploidy discussed for other taxa in the Harris (2008) paper. Although each of the last two species is attributed morphological and ecological differences between at least some geographically disjunct populations, this phenomenon warrants additional attention. Given that $P$. maximoviczii is thrice heterophyletic and P. integrum twice in the Harris (2008) molecular cladogram, the relationship may be an important evolutionary laboratory for further research.

Even papers with no or little indication of reliability of molecular phylogenies can offer hypotheses or at least instruction, though emphasis on statistical power (Zander, 2007a), that can be pursued with more data and deeper taxonomic coverage. For instance, a combined molecular and morphological study of Pogonatum by Koshinen \& Hyvönen (2004) found exemplars of P. pennsylvanicum (W. Bartram ex Hedw.) P. Beauv. polyphyletic. Closer analysis found that the heterophyly was due to the lack of data on one sequence for one (of three) exemplar of that species. A molecular-morphological phylogeny of the Polytrichales by Hyvönen \& al. (2004) demonstrated heterophyly that was discussed by the authors as possibly due to long-branch attraction. The alternative explanation of multiple surviving ancestors postulated in the present paper suggests that a deep virtual fossil (resolvable at the genus level of) Oligotrichum give rise to complex molecular lineages involving the genera Atrichum, Italiella, Meiotrichum, Notoligotrichum, Psilopiloum, and Steereobryon, and also to another virtual fossil resolvable as the genus Pogonatum, which itself gave rise to Eopolytrichum and Polytrichastrum.

This has been an introduction of the use of apparent surviving ancestors to infer at least short evolutionary series of macroevolution in mosses and posing some interesting questions that are amenable to further research given the existence of living representatives of inferred ancestors. Other publications exist that include large numbers of exemplars that could allow evolutionary inferences at the species or genus level, but the nomenclature may be already be much modified to fit phylogenetic strictures of monophyly (e.g. Huttunen \& al., 2004) or the support values may not be quite high enough for adequate resolution (e.g. Gardiner \& al., 2005), requiring additional analysis (e.g. following Zander, 2007a) more appropriate for a different paper.

\section{Discussion}

That mosses may exhibit evidence of punctuated evolution (bursts of speciation followed by long stasis) is supported by geologic fossil evidence. Although mosses have changed little in the past 300 million years, the oldest from the Upper Devonian and principal groups distinguishable before the end of the $\mathrm{Pa}$ leozoic (Lacey, 2008), of 40 Miocene and 79 Pliocene known European species of mosses (Dickson, 1973), all but four are modern taxa (Frahm, 1994). Recently an Andean moss species "indistinguishable from the extant Drepanocladus longifolius" was found in midMiocene deposits of continental Antarctica (Lewis \& al., 2008). The Madeiran endemic Brachythecium percurrens Hedenäs, on the basis of fossil calibration and absolute rates of nucleotide exchange, is apparently a relictual Eocene species with static morphology over the past 40 million years, well before the present habitat emerged from the sea (Vanderpoorten \& al., 2009). According to Konopka \& al. (1998), extant moss families, and in some cases extant genera of mosses diversified by the Late Cretaceous. It is well known that continental disjunctions of moss species and genera apparently parallel at those taxonomic levels those of vascular plant genera and families (Herzog, 1926). This "slow evolution" of mosses may be due to strong stabilizing evolution associated with narrow niches and microhabitats.

Assumed in such standard phylogenetic terminology as "sister groups" and "shared ancestry" is the idea that products of evolution signaled by phylogenetic 
splitting must be new taxa, and there are no or very few surviving ancestors. Phylogenetically disjunctive exemplars of the same taxon showing "massive homoplasy" of phenotypic traits on published molecular cladograms, on the other hand, apparently contravene Dollo's Law $(\mathrm{Hall}, 2003)$ that complex traits cannot be expected to re-evolve (short of invoking orthogenesis). These may be taken, in fact, as probabilistic evidence of deeply buried shared ancestral taxa, although such heterophyly is commonly interpreted in phylogenetics as calling for massive rearrangements in classification. At the genus and species level, phylogenetic nesting on the basis of molecular trait changes may be accurate, but any one ancestral species may be phylogenetically complex, e.g., the domestic cat species (Driscoll \& al., 2007), any split in a molecular lineage may involve one or more populations of a surviving ancestor, and "evolution" as changes in mostly non-coding DNA base changes is scarcely as important to systematics as descent of taxa with modification of expressed traits. Molecular lineages, however, do provide a window on genetic continuity, except, of course, in the case of hybridization or lateral gene transfer, in which case other data must be used to resolve incongruities.

A virtual fossil is an inferred taxonomically diagnosable direct ancestor. It comprises two or more nodes on a molecular tree, and has the same or higher rank than that represented by the two or more extant exemplars. Virtual fossil analysis is independent of species concept, except phylogenetic species concepts intolerant of the concept of a single taxon being present in two or more molecular lineages at once. This includes incomplete reciprocal monophyly where the populations of differentiating species may be initially paraphyletic but assumes, sometimes wrongly, that eventual extinction of assorted genetic lines must lead to monophyly. It is possible that virtual fossils, like geologic fossils, may be dated. Certainly a minimum date would be an estimate of the length of time that molecularly different populations of isophenotypic exemplars were isolated, e.g. that of continental drift. Given a molecular clock, even if approximate, other methods could be used to date shared ancestors of heterophyletic exemplars of the same taxon.

Promoters of the use of molecular phylogenies in systematics commonly invoke the idea of "cryptic species" for what is here interpreted as shared phenotaxon ancestry involving surviving ancestors (species, genera, etc.). In many cases cryptic species discovered with molecular analysis such as barcoding (Hebert \& Gregory, 2005; Kress \& al., 2005; New- master \& al., 2006) may indeed be associated later with diagnosable morphological or life history traits (Hebert \& al., 2004; Hillis \& al., 1996: 519). One must be wary, however, of multiple-test problems, in that there may be two alternative morphological sets of traits associated with phylogenetic recognition of nearly any two different almost fully cryptic groups but molecular support is not support for one of them simply because morphology and DNA by chance agree (Zander, 2007a, c). In many cases, on the other hand, the species remain fully cryptic, that is, phylogenetically disjunctive isophenes (e.g. Elmer \& al., 2007).

Presently, the emphasis in phylogenetics is on using parsimony or coalescent theory Bayesian analysis on data sets of randomly mutating DNA sequence traits that theoretically track lineages of phenotypic or at least biological speciation. Although such molecular lineages apparently are statistically demonstrable, when conflicts occur with the results of morphological analyses or when resolution is needed in morphological analyses, the relationship between a molecular split and a speciation event is commonly based solely on the biological species concept requiring speciation after an event of isolation (e.g., as criticized by Rieseberg \& Burke, 2001). This does not apply to many if not most groups of organisms. Systematics is gradually becoming based primarily on this molecular foundation, isolating itself from fields, such as population biology, ecology, evolution, and biogeography, that investigate or use theories of evolution based largely on expressed traits. Theories in science, particularly quasi-experimental (Cook \& Campbell, 1979) or historical fields whose assumptions and results are not directly verifiable, are often easily generated and if internally consistent may be sustained by pure reason in the absence of empiric data (Hey, 2001). This is particularly true in systematics where the theoretic scaffolding for progression of evolutionary change in species is poorly resolved or understood because of a lack of facts, beyond that of evolution itself, and thus fact-based theory. Pieces of the puzzle are easily filled in by appeal to simplicity, a fancied similarity to the Principle of Least Action in physics. The latter, however, is quite solidly based in observation, while parsimony of tree length, or probabilities of branch coalescence, are at a remove from corroborative observations of details of descent with modification of taxa as to their expressed or unexpressed traits.

According to Arendt \& Resnick (2007), because genomic analysis has demonstrated that the same genes may be involved in the same phenotypic adaptation in phylogenetically distant groups of animals, 
while different genes are apparently the source of the same phenotypic adaptation in related groups, the usual distinction between parallelism and convergence (parallelism expected to be based on the same genomic pathways, and convergence on different) breaks down. The authors recommend that "convergence" should be the general term. As this applies to the present paper, evolution of the phenotype may be quite disconnected from evolution of the genotype though remaining based on it. Although homologous features are derived from common ancestors, nonhomologous features may also, and, if these are part of the same lineage, they are not convergent (or parallel) but simply are substitutions of one gene system for another in support of the same evolutionary feature as no more than a kind of anagenesis along one line of evolution, this tracked by the molecular data. Convergence is indeed the general term but the phenomenon is informative, not confounding.

Watson (1913) presented a long list of morphological features of mosses that he inferred to be adaptations to periodic drying of habitats. Patterson (1964), however, in a review of experimental studies, concluded that physiological responses were far more important than morphological traits in determining resistance to desiccation, suggesting that Watson's list of traits lacked any basis in fact. Anderson (1974), on the other hand, in a review of experimental physiology, suggested that the morphology of mosses is probably of some importance in determining their ability to live in dry habitats. Certainly many Pottiaceae with apparent elaborate adaptations to harsh environments (leaves with hair points, papillae, and inflated basal cells, reduced capsules with large spores) grow side-by-side with Bryaceae and Ditrichaceae, these with little apparent morphological adaptation. With the present technique detailing macroevolution, however, correlations of trait changes and habitat may prove illustrative of selection on the basis of morphology rather than physiology.

Tests of the virtual fossil method need to be developed. Of course the most obvious tests are whether the method (a) fits the facts, which it does as discussed above, and (b) whether it melds well with evolutionary theory. Although evolution is a fact, theory on the mechanisms of evolution is still in vigorous flux (Gould, 1983), and it is here hoped that the inferred relationships of virtual fossils on molecular trees might illuminate aspects of such theory given that surviving ancestors are available for study. A second test might involve co-evolution of organisms and their parasites, pollinators, or predators; the latter might be expected to similarly diverge in molecular traits but retain phenological characteristics.

It is here hoped that the difficult task of retrodicting phenotypic evolution of taxa diagnosed by expressed traits is not abandoned in adhering to the past paradigm change of substituting molecular phylogenies for taxon trees in systematics. Declaring a difficult problem solved by simply changing the matter under scientific investigation because a different problem is more tractable is not helpful and is even doubtfully a paradigm change since different subjects are addressed.

It is only an importunate homage on the part of phylogeneticists to their sister-group analytic method that requires enforcement of strict phylogenetic monophyly (holophyly) in modern classifications, splitting, excising, or reducing in rank taxa that should have unique evolutionary traits flagged at an appropriate level in classification. Because ancestordescendant relationships and lineages probably affected by punctuated equilibria are not recognized in phylogenetic classification, a major source of evolutionary information is gradually being deleted from the classifications that inform biodiversity and evolutionary study. This isolates systematics, which presently cannot or will not provide a general-purpose classification.

Hull (1979) has pointed out that genealogy and divergence cannot both be represented in a classification and be separately retrievable. Although this is true, the existence of ancillary cladograms and taxon trees allows distinction of which taxa are flagged by higher taxonomic level because they are sister groups to major lineages or because they are significantly unique autophyletic descendants. A classification including both types are information would be of greater value to ecologists, morphologists, evolutionists, students of evol-devo, teachers, government, and so on, certainly of greater pragmatic value than a special-purpose classification of interest largely only to phylogeneticists.

\section{Acknowledgements}

I thank R.K. Brummitt, R. Mesibov, and others for comments on various drafts of this paper. The abiding encouragement of P.M. Eckel is much appreciated. Thanks are due the Missouri Botanical Garden for on-going support of this research.

\section{References}

Alfaro, M.E. \& Huelsenbeck J. P. 2006. Comparative performance of Bayesian and AIC-based measured of phylogenetic model uncertainty. Systematic Biology 55: 89-96. 
Anderson, L.E. 1974. Bryology, 1947-1972. Annals of the Missouri Botanical Garden 61: 56-85.

Arendt, J. \& Reznick, D. 2007. Convergence and parallelism reconsidered: what have we learned about the genetics of adaptation? Trends in Ecology and Evolution 23: 26-32.

Benton, M.J. \& Pearson, P.N. 2001. Speciation in the fossil record. Trends in Ecology and Evolution 16: 405-411.

Bessey, C.E. 1915. The phylogenetic taxonomy of flowering plants. Annals of the Missouri Botanical Garden 2: 109-233.

Bowler, P.J. 1989. Evolution: The History of an Idea. Univ. California Press, Berkeley.

Brummitt, R.K. 2002. How to chop up a tree. Taxon 51: 1-41.

Caporale, L.H. 1999. Chance favors the prepared genome. Annals of the New York Academy of Sciences, U.S.A. 870: 1-21.

Caporale, L.H. 2003. Natural selection and the emergence of a mutation phenotype: an update of the evolutionary synthesis considering mechanisms that affect genome variation. Annual Review of Microbiology 57: 467-485.

Cook, T.D. \& Campbell, D.T. 1979. Quasi-Experimentation: Design and Analysis Issues for Field Settings. Rand McNally College Publishing Co., Chicago.

Cronquist, A. 1975. Some thoughts on angiosperm phylogeny and taxonomy. Annals of the Missouri Botanical Garden 62: $517-$ 520.

Cronquist, A. 1987. A botanical critique of cladism. Botanical Review 53: 1-52.

Crum, H.A. \& Anderson, L.E. 1980. Mosses of Eastern North America. 2 Vols. Columbia Univ. Press, New York.

Dayrat, B. 2005. Ancestor-descendant relationships and the reconstruction of the Tree of Life. Paleobiology 31:347-353.

Deméré, T.A., McGowen, M.R, Berta, A. \& Gatesy, J. 2008. Morphological and molecular evidence for a stepwise evolutionary transition from teeth to baleen in mysticete whales. Systematic Biology 57: 15-37.

Donoghue, M.J. \& Cantino, P.D. 1988. Paraphyly, ancestors, and the goals of taxonomy: A botanical defense of cladism. Botanical Review 54: 107-128.

Doyle, J.J. 1996. Homoplasy connections and disconnections: Genes and species, molecules and morphology. In: Sanderson, M.J. \& Hufford, L. (eds.), The Recurrence of Similarity in Evolution. Academic Press, New York. Pp. 37-66.

Driscoll, C.A., Menotti-Raymond, M., Roca, A.L., Hupe, K., Johnson, W.E., Geffen, E., Harley, E., Delibes, M., Pontier, D., Kitchener, A.C., Yamaguchi, N., O’Brien, S.J. \& Macdonald, D. 2007. The Near Eastern origin of cat domestication. Science 317: 519-523.

Eckel, P.M. 1998. A re-evaluation of Tortella (Musci, Pottiaceae) in conterminous U. S. A. and Canada with a treatment of the European species of Tortella nitida. Bulletin of the Buffalo Society of Natural Sciences 36: 117-191.

Eldredge, N. \& Gould, S.J. 1972. Punctuated equilibria: an alternative to phyletic gradualism. In: Schopf, T.J.M. (ed.), Models in Paleobiology. Freeman, Cooper \& Co., San Francisco. Pp. $82-115$.

Elmer, K.R., Davila, J A. \& Lougheed, S.C. 2007. Cryptic diversity and deep divergence in an upper Amazonian frog, Eleutherodactylus ockendeni. BMC Evolutionary Biology 7: 247. doi: 10. 1186/1471-2148-7-247.

Endress, P.K. 1996. Homoplasy in angiosperm flowers. In: Sanderson, M.J. \& Hufford, L. (eds.), The Recurrence of Similarity in Evolution. Academic Press, New York. Pp. 303-325.

Farjon, A. 2007. In defense of a conifer taxonomy which recognises evolution. Taxon 56: 639-641.
Foote, M. \& Miller, A.I. 2006. Principles of Paleontology. W.H. Freeman, New York.

Frahm, J.-P. 1994. Moose-lebende Fossilien. Biologie in unseren Zeit 24: 120-124.

Futuyma, D.J. 1998. Evolutionary Biology. Third Edition. Sinauer Associates, Sunderland, Massachusetts.

Gardiner, A., Ignatov, M., Huttunen, S. \& Troitsky, A. 2005. On resurrection of the families Pseudoleskeaceae Schimp. and Pylaisiaceae Schimp. (Musci, Hypnales). Taxon 54: 651-663.

Gauthier, J. 2001. Feathered dinosaurs, flying dinosaurs, crown dinosaurs, and the name "Aves." In: Gauthier, J. \& Gall, L.F. (eds.), New Perspectives on the Origin and Early Evolution of Birds: Proceedings of the International Symposium in Honor of John H. Ostrom. Peabody Museum of Natural History, Yale University, New Haven, Connecticut.

Goffinet, B., Buck, W.R. \& Shaw, A.J. 2008. Morphology and classification of the Bryophyta. In: Goffinet, B. \& Shaw, A.J. (eds.), Bryophyte Biology, 2nd Edition. Cambridge University Press. Pp. 55-138,

Gould, S.J. 1983. Hen's Teeth and Horse's Toes. W.W. Norton \& Company, New York. Pp. 253-262.

Gould, S.J. \& N. Eldredge. 1977. Punctuated equilibria: the tempo and mode of evolution reconsidered. Paleobiology 3: 115151.

Gould, S.J. \& Eldredge, N. 1993. Punctuated equilibrium comes of age. Nature 366: 223-227.

Gould, S.J. \& Lewontin, R.C. 1979. The spandrels of San Marco and the Panglossian paradigm: a critique of the adaptationist programme. Proceedings of the Royal Society, London B 205: 581-598.

Grant, V. 1971. Plant Speciation. Columbia University Press, New York.

Guillaumet, A., Crochet, P.-A. \& Pons, J.-M. 2008. Climate-driven diversification in two widespread Galerida larks. BMC Evolutionary Biology 8: 32. doi: 10. 1186/1471-2148-8-32.

Hall, B.K. 2003. Descent with modification: the unity underlying homology and homoplasy as seen through an analysis of development and evolution. Biological Review 78: 409-433.

Harris, E.S.J. 2008. Paraphyly and multiple causes of phylogenetic incongruence in the moss genus Plagiomnium (Mniaceae). Taxon 57: 417-433.

Hebert, P.D.N., Penton, E.H., Burns, J.M., Janzen, D.H. \& Hallwachs, W.. 2004. Ten species in one: DNA barecoding reveals cryptic species in the neotropical skipper butterfly $A s$ traptes fulgerator. Proceedings of the National Academy of Sciences, U.S.A. 101: 14812-14817.

Hebert, P.D.N. \& Gregory, T. 2005. The promise of DNA barcoding for taxonomy. Systematic Biology 54: 842.

Hedenäs, L. 2008. Molecular variation and speciation in Antitrichia curtipendula s. 1. (Leucodontaceae, Bryophyta). Botanical Journal of the Linnean Society 156: 341-354.

Hedenäs, L. \& Eldenäs, P. 2007. Cryptic speciation, habitat diffeentiation, and geography in Hamatocaulis vernicosus (Calliergonaceae, Bryophyta). Plant Systematics and Evolution 268: 131-145.

Hernández-Maqueda, R., Quandt, D., Werner, O. \& Muñoz, J. 2008. Phylogeny and classification of the Grimmiaceae/Ptychomitriaceae complex (Bryophyta) inferred from cpDNA. Molecular Phylogenetics and Evolution 46: 863-877.

Herzog, T. 1926. Die Geographie der Moose. Jena. 
Hey, J. 2001. The mind of the species problem. Trends in Ecology and Evolution 16:326-329.

Hey, J. \& Kliman, R.M. 1993. Population genetics and phylogenetics of DNA sequence variation at multiple loci within the Drosophila melanogaster species complex. Molecular Biology and Evolution 10: 804-822.

Hörandl, E. 2006. Paraphyletic versus monophyletic taxa-evolutionary versus cladistic classifications. Taxon 55: 564-570.

Hörandl, E. 2007. Neglecting evolution is bad taxonomy. Taxon 56: $1-5$.

Hull, D. L. 1979. The limits of cladism. Systematic Zoology 28: 416440.

Huttunen, S., Ignatov, M.S., Muller, K. \& Quandt, D. 2004. Phylogeny and evolution of epiphytism in the three moss families Meteoriaceae, Brachytheciaceae, and Lembophyllaceae. Monographs in Systematic Botany 98: 328-364.

Jardin, N. \& Sibson, R. 1971. Mathematical Taxonomy. John Wiley $\&$ Sons, New York.

Kliman, R.M. \& Hey, J. 1993. DNA sequence variation at the period locus within and among species of the Drosophila melanogaster complex. Genetics 133: 375-387.

Konopka, A.S., Herendeen, P.S. \& Crane, P.R. 1998. Sporophytes and gametophytes of Dicranaceae from the Santonian (Late Cretaceous) of Georgia, USA. American Journal of Botany 85: 714-723.

Koshinen, S. \& Hyvönen, J. 2004. Pogonatum (Polytrichales, Bryophyta) revisited. Pp. 255-269. In: Goffinet, B., Hollowell, V. \& Magill, R. (eds.), Molecular Systematics and Bryophytes. Missouri Botanical Garden Press, St. Louis.

Kress, W.J., Wurdack, K.J., Zimmer, E.A., Weigt, L.A. \& Janzen, D.H. 2005. Use of DNA barcodes to identify flowering plants. Proceedings of the National Academy of Sciences, U.S.A. 102: 8369-8374

Lacey, W.S. 2008. Fossil bryophytes. Biological Reviews 44: 189205.

Leschen, R.A.B., Buckley, T.R., Harman, H.M. \& Shulmeister, J. 2008. Determining the origin and age of the Westland beech (Nothofagus) gap, New Zealand, using fungus beetle genetics. Molecular Ecology 17: 1256-1276.

Levin, D.A. 2001. 50 years of plant speciation. Taxon 50: 69-91.

Lewis, A.R., Marchant, D.R., Ashworth, A.C., Hedenäs, L., Hemming, S.R., Johnson, J.V., Leng, M.J., Machlus, M.L., Newton, A.E., Raine, J.I., Willenbring, J.K., Williams, M. \& Wolfe, A.P. 2008. Mid-Miocene cooling and the extinction of tundra in continental Antarctica. Proceedings of the National Academy of Sciences 105: 10676-10680.

Lewis, H. 1962. Catastrophic selection as a factor in speciation. Evolution 16: 257-71.

MacFadden, B.J. 1992. Fossil Horses: Systematics, Paleobiology, and Evolution of the Family Equidae. Cambridge University Press, New York.

Moritz, C., Schneider, C.J. \& Wake, D.B. 1992. Evolutionary relationships within the Ensatina eschscholtzii complex confirm the ring species interpretation. Systematic Biology 41: 273-291.

Nelson, G., Murphy, D.J. \& Ladiges, P.Y. 2003. Brummitt on paraphyly: a response. Taxon 52: 295-298

Newmaster, S.G, Fazekas, A.J. \& Ragupathy, S. 2006. DNA barcoding in land plants: evaluation of rbcL in a multigene tiered approach. Canadian Journal of Botany 84: 335-341.

Patterson, P.M. 1964. Problems presented by bryophytic xerophytism. Bryologist 67: 390-396.
Rensch, B. 1960. Evolution Above the Species Level. Methuen \& Co. Ltd., London. English translation 1959. Columbia University Press.

Rieseberg, L.H. \& Brouillet, L. 1994. Are many plant species paraphyletic? Taxon 43: 21-32.

Rieseberg, L.H. \& Burke, J.M. 2001. A genic view of species integration. Journal of Evolutionary Biology 14: 883-886.

Shaw, J. 2001. Biogeographic patterns and cryptic speciation in bryophytes. Journal of Biogeography 28: 253-261.

Shaw, J.A., Holz, I., Cox, C.J. \& Goffinet, B. 2008. Phylogeny, character evolution, and biogeography of the Gondwanic moss family Hypopterygiaceae (Bryophyta). Systematic Botany 33: 21-30.

Shen, Bing, Lin Dong, Shuhai Xiao \& Kowalewski, M. 2008. The Avalon explosion: evolution of Ediacara morphospace. Science 319: 81-84.

Stanley, S.M. 1975. A theory of evolution above the species level. Proceedings of the National Academy of Sciences 72: 642-650.

Stebbins, G.L. 1974. Flowering Plants: Evolution Above the Species Level. Harvard University Press, Cambridge.

Theriot, E. 1992. Clusters, species concept, and morphological evolution of diatoms. Systematic Biology 41: 141-157.

Vanderpoorten, A., Algoin, D., Devos, N, Huttunen, S. \& Ignatov, M. 2009. [Abstract] And if Engler was not completely wrong? Evidence for a mixture of neo- and paleoendemism in the moss flora of Macaronesia. Botany and Mycology 2009, Bryological and Lichenological Section. http://2009.botanyconference.org/ engine $/$ search $/$ index.php? func $=$ detail\&aid $=161$.

Vrba, E.S. 1984. Evolutionary pattern and process in the sistergroup Alcelaphini-Aepycerotini (Mammalia:Bovidae). In: Eldredge, N. \& Stanley, S.M. (eds.), Living Fossils. Springer-Verlag, New York. Pp. 62-79.

Watson, W. 1913. Xerophytic adaptations of bryophytes in relation to habitat. New Phytologist 13: 149-169, 181-190.

Werner, O., Ros, R.M., Cano, M.J. \& Guerra, J. 2004. Molecular phylogeny of Pottiaceae (Musci) based on chloroplast rps4 sequence data. Plant Systematics and Evolution 243: 147-164.

Werner, O., Ros, R.M. \& Grundmann, M. 2005. Molecular phylogeny of Trichostomoideae (Pottiaceae, Bryophyta) based on nrITS sequence data. Taxon 54:361-368.

Whittaker, R.H. 1972. Evolution and measurement of species diversity. Taxon 21: 213-251.

Wiley, E.O. \& Mayden, R.L. 2000. The evolutionary species concept. In: Wheeler, Q.D. \& Meier, R. (eds.), Species Concepts and Phylogenetic Theory: A Debate. Columbia University Press, New York. Pp. 70-89; 146-158; 198-208.

Witmer, L.M. 1995. The extant phylogenetic bracket and the importance of reconstructing soft tissues in fossils. In: Thomason, J.J. (ed.), Functional Morphology in Vertebrate Paleontology. Cambridge University Press, Cambridge, U.K. Pp. 19-33.

Witmer, L.M. 1998. Application of the extant phylogenetic bracket (EPB) approach to the problem of anatomical novelty in the fossil record. Journal of Vertebrate Paleontology 18(3: Suppl.): $87 \mathrm{~A}$.

Zander, R.H. 1977. The tribe Pleuroweisieae (Pottiaceae, Musci) in Middle America. Bryologist 80: 233-269.

Zander, R.H. 1998. A phylogrammatic evolutionary analysis of the moss genus Didymodon in North America North of Mexico. Bulletin of the Buffalo Society of Natural Sciences 36: $81-115$. 
Zander, R.H. 2007a. Nine easy steps for constructing reliable trees from published phylogenetic analyses. Annals of the Missouri Botanical Garden 94: 691-709.

Zander, R.H. 2007b. Paraphyly and the species concept, a reply to Ebach \& al. Taxon 56: 642-644.

Zander, R.H. 2007c. When biodiversity study and systematics diverge. Biodiversity 8: 43-48.

Zander, R.H.. 2007d. The Pottiaceae s. str. as an evolutionary Lazarus taxon. Journal of the Hattori Botanical Laboratory 100: 581-602.
Zander, R.H. 2008a. Statistical evaluation of the clade "Rhabdoweisiaceae”. Bryologist 111: 292-301.

Zander, R.H.. 2008b. Evolutionary inferences from nonmonophyly of traditional taxa on molecular trees. Taxon 57: 11821188.

Associate Editor: J. Guerra

Received: 25-II-2009

Accepted: 28-V-2009 
